\title{
A Human Ecology Approach to Environmental Inequality: A County- Level Analysis of Natural Disasters and the Distribution of Landfills in the Southeastern United States
}

\author{
Laura McKinney ${ }^{1}$ \\ Department of Sociology, Tulane University, Louisiana, \\ United States \\ Edward Kick \\ Department of Agriculture and Resource Economics, North \\ Carolina State University, United States \\ Clare Cannon \\ Tulane University, Louisiana, United States
}

\section{Abstract}

One underexplored area of great concern is the relationship between disasters and disposition of the waste they generate, which often amounts to the equivalent of 5 to 15 years of garbage that the same community would create under normal conditions. This paper develops a theoretical framework to analyze the factors that influence the distribution of landfills by integrating insights gained from the environmental inequality and human ecology traditions. The synthesis informs the quantitative analysis of the distribution of landfills across counties in the southeastern region of the United States by examining crucial associated variables, disasters, and other relevant factors gleaned from prior research. Findings suggest that natural disasters have indirect relationships with other communities that process waste. Results also point to the disproportionate concentration of landfills in counties with greater minority populations. The conclusions and implications of the findings are discussed in addition to a range of potential applications for future research.

Keywords: environmental inequality, human ecology, landfills, natural disasters, POET model

1 Corresponding author: lauramc@tulane.edu. 


\section{Introduction}

The horrific effects of natural disasters make it a topic of immediate and significant concern, yet there is a near total lack of examination of the effects of natural disasters on important problems, such as landfill waste. Global warming ${ }^{2}$ trends affect society in numerous ways, with international scientific consortiums identifying the increased frequency and magnitude of extreme weather events as one such outcome (IPCC, 2007). In their recent review of the field, Rudel et al. (2011:233) conclude that, "Under these circumstances, disasters, community resilience after disasters, and the political economy of relief and mitigation efforts should become important foci for more theoretical work." Following their call, this paper theoretically develops and empirically analyzes the relationship of natural disasters and the distribution of landfills in the southeastern United States. Examining this connection reflects an especially important facet of community resilience and recovery post-disaster, as clearing waste and debris is one of the fundamental challenges to a successful recovery (Brown et al., 2011; EPA, 2008; Luther, 2008).

The linkages that connect natural disasters and waste are much deeper than a one-way relationship whereby natural disasters create vast amounts of waste: The accumulation of waste in landfills accelerates the generation of greenhouse gases (e.g., methane, carbon dioxide) that contribute to climate change, which in turn leads to more frequent and intense disasters producing even larger volumes of landfill waste (EPA, 2006, 2013a). Particularly important is the influence of methane, which is the second-largest contributor to the greenhouse effect with a warming potential estimated to be 20 times greater than carbon dioxide (Lelieveld, 2006:405). Methane is a by-product of a number of natural processes, but its prevalence in the atmosphere has witnessed a recent upsurge mostly due to anthropogenic sources (Forster et al., 2007). Methane-reduction strategies cite the accumulation of organic waste in landfills, primarily in developed countries, as central targets given their substantial contributions of such emissions (Hogan et al., 1991; EPA, 2006, 2013a).

Further, disasters can decimate existing forestlands in the course of their destruction and subsequently precipitate the harvesting of wood to rebuild, which are additional links to global climate change as the removal of trees reduces the amount of carbon dioxide sequestered from the atmosphere via

\footnotetext{
2 The authors immediately note differences in the terminology used to refer to "global warming." Some believe "global warming" is subject to misinterpretation because it does not reflect the entirety of outcomes related to the greenhouse effect, which include changes in precipitation, wind patterns, and even humidity, and prefer "climate change" as a better descriptor. Leading climate scientist in America James Hansen advocates for "global climate disruption" to characterize the process of and outcomes related to anthropogenic stress on the climate. Global warming and climate change rank top in the popular vernacular and are used interchangeably in this paper.
} 
photosynthesis. Yet another tie is the emission of greenhouse gases incurred in the collection, transport, and burying or burning of trash in the wake of a disaster (EPA, 2013a). The degree to which global climate change is posited to result from the release and trapping of greenhouse gases in the atmosphere underscores the importance of critically evaluating disaster events and the myriad environmental losses they bring. As such, it is important for theoretical and empirical progress in the field that we begin to consider the cycles that connect these key environmental dynamics.

Notably, theory and empirics on the topics of climate change (e.g., Roberts \& Parks, 2007), disasters (e.g., Fothergill \& Peek, 2004), and landfills (e.g., Mohai \& Saha, 2007) jointly emphasize that marginalized populations suffer disproportionate exposure to such adversities and their effects (for review see Brulle \& Pellow, 2006; Mohai et al., 2009). Thus, not only are these topics linked in ways that perpetuate and exacerbate one another, but they are also connected in their relative contributions to widening gaps of inequality. Despite their importance, it is extremely rare for analyses to examine the relationship between disasters and landfills, which is one gap this paper seeks to fill. ${ }^{3}$

\section{Disasters and waste}

To contextualize the amount of waste produced by disaster events, the EPA (2013b) reports that in 2011 the United States generated 250 million tons of municipal solid waste while Hurricane Katrina in 2005 created approximately 113.5 cubic yards (227 million tons) $)^{4}$ of waste (Luther, 2008). Generally, disasters generate the equivalent of 5 to 15 years' worth of waste in a matter of days (Brown et al., 2011), with clear implications for overwhelming waste disposal facilities. Disaster debris is a wide-ranging category with potential impacts on all types of landfills, as there are vegetative (fallen trees, yard waste), municipal (household trash), construction and demolition (C\&D) (concrete, lumber, metals, drywall, roofing, and other demolition materials), hazardous (oil, pesticides), industrial (commercial buildings and materials), and structural (downed power lines, unearthed septic tanks, collapsed roadways and bridges) types of waste to be removed. Depending on the severity of the event, removing debris often presents the single most challenging hurdle to recovery (Brown et al., 2011; Luther, 2008).

There are short- and long-term considerations for clearing disaster debris. Human health concerns most immediately dictate the swift removal and

3 In fact, the authors are unaware of any analysis in sociology or its related disciplines that empirically tests the relationship between natural disasters and landfills.

4 Although the conversion from yards to tons depends on the type of materials, doubling the number of tons to estimate cubic yards is used by EPA disaster waste management authorities (Luther, 2008:3). 
subsequent disposal of waste that poses the greatest threat to individuals. For example, following Hurricane Katrina and the levee breach that flooded New Orleans, the Army Corps of Engineers removed some 36 million pounds of rotten food from local storage facilities to curb rodent infestation and associated illnesses (Luther, 2008:4). In the overwhelming surge of disposal demands, communities would benefit from using alternative techniques to process waste (e.g., recycling, burning) $)^{5}$ in an effort to divert as much as possible from landfills. Unfortunately, a lack of disaster preparedness is a major hurdle to implementing these alternative waste management practices on a widespread basis (Brown et al., 2011; Luther, 2008). Disasters often occur without much notice ${ }^{6}$ (if any at all) and communities are left to deal with the aftermath in the absence of predisaster planning, including techniques to process waste that are less impactful on landfill capacities. ${ }^{7}$ In the long-run, it is acutely important that communities dispose of disaster waste in ways that prevent contamination and toxicity of the air, land, and water sources.

Disaster waste is especially prone to improper disposal, as the desire for a speedy recovery takes precedence over future troubles instigated by contamination. The sheer volume of waste post-disaster amplifies the likelihood that hazardous waste will be improperly disposed of in landfills that are not equipped to minimize threats to human health and the environment. Thus, virtually all landfills are vulnerable to post-disaster use and contamination by commingled hazardous and non-hazardous waste (Luther, 2008). Despite mighty efforts by the Army Corps of Engineers to implement optimal methods of segregating and disposing of waste after Hurricane Katrina, most of the debris "was mixed to the point that separation [was] either difficult or essentially impossible" (Luther, 2008:10).

While federal mandates regulate the standards of operation for municipal solid waste and hazardous waste landfills, ${ }^{8}$ individual states are charged with establishing operating criteria for other landfill types (e.g., C\&D; industrial). This is especially consequential for disaster debris, the bulk of which is C\&D

\footnotetext{
5 We acknowledge there are additional environmental concerns posed by incineration techniques, most notably the air pollution that results.

6 Some disasters (e.g., earthquakes) occur with little or no warning, others (e.g., hurricanes) might elicit some advanced notice, most of which is dedicated to evacuation and protection. Furthermore, predicting the severity of disasters is wrought with uncertainty.

7 Although some communities have excelled in pre-disaster planning, in general, local governments are especially overburdened in the current era of neoliberalism and federal government rollback, which shifts responsibilities from the federal to local governmental bodies, the latter of which have inferior monetary and human capital assets (see e.g., Tierney, 2012).

8 The United States Environmental Protection Agency (EPA) regulates the location, operation, design, control, monitoring, closure, post-closure maintenance, and financial solvency criteria for municipal solid waste landfills under subtitle D of the Resource Conservation and Recovery Act; subtitle C of the Act regulates the same for hazardous waste landfills.
} 
waste that lacks federal regulation. ${ }^{9}$ To illustrate, $C \& D$ landfills are not subject to federal mandates that require their municipal solid waste counterparts to have protective liners, control leachate, and collect runoff. States also define what constitutes $C \& D$ waste, and often in the aftermath of a disaster, choose to relax their definitions to expedite removal and disposal. ${ }^{10}$ This was precisely the case after Hurricane Katrina when the Louisiana Department of Environmental Quality expanded acceptable C\&D waste to include "construction and demolition debris with asbestos contaminated waste" (Luther, 2008:11). These complex circumstances apply to four landfills in the New Orleans area and therefore warrant consideration.

Amid the horrific tragedy brought about by the levee failure in the aftermath of Hurricane Katrina, officials were faced with multiple controversial decisions. Among those was the designation of four landfills in the greater New Orleans area-Gentilly, River Birch, Highway 90, and Chef Menteur - to dispose of disaster waste. The ensuing saga was reported in The Times-Picayune (Russell, 2012) and The New York Times (Eaton, 2006). Prior to Katrina, Highway 90 operated as a C\&D landfill while River Birch was permitted to accept municipal solid waste. The storm's wreckage spiked dumping in Highway 90 by 2,400 percent in the year following the flood (Louisiana Department of Environmental Quality, as reported in Russell, 2012); meanwhile, the Old Gentilly Dump and Chef Menteur landfills were given emergency permits to accept C\&D waste. Local environmentalists, who remembered the Superfund site that resulted from the reopening of Agriculture Street dump after Hurricane Betsy, initiated a firestorm of protests and campaigns to suspend the emergency-issued permits. Their concern was compounded by the fact that the Chef Menteur landfill secured a zoning waiver to permit its operation, which is located next to the Bayou Sauvage National Wildlife Refuge with close proximity to a largely Vietnamese community. The following statement of concern was issued by the Louisiana Field Office of the U.S. Fish \& Wildlife Service:

Given the scope and nature of the flooding events and the age of many of the buildings to be demolished and deposited in the proposed landfill, we believe that the delivery of materials containing numerous environmental contaminants, such as lead-based paint, asbestos, creosote, arsenic-based wood treatment chemicals, various petroleum products, and a variety of pesticides and household cleaning chemicals would be unavoidable. Placement of such materials in an unlined landfill,

9 In fact, the Sierra Club sued the EPA for failing to regulate C\&D landfills that receive hazardous waste from conditionally exempt small quantity generators (CESQGs - those that generate less than 100 kilograms of hazardous waste per month).

10 Importantly, "demolition" waste is far more likely to be contaminated than "construction" waste, and the former constitutes the bulk of post-disaster debris. 
particularly within coastal wetlands, could potentially result in leaching and resultant persistent contamination of ground water, surface water and adjacent wetland habitats. (quoted in Luther, 2008:13)

After operating for four months and handling tons of debris, the Chef Menteur landfill was closed due to failure to obtain a conventional permit - a decided victory in the eyes of surrounding neighborhoods and local environmental advocates. We likely do not yet know the full extent of damage exacted on communities receiving post-Katrina waste, especially in light of modified definitions of acceptable waste and emergency permits. In this case and most instances of disaster waste, the desire for timely removal takes precedence over enforcing the segregation and proper disposal of contaminated waste.

\section{Environmental inequality}

Most agree that the fight against environmental inequality began in 1982 in Warren County, North Carolina, when word spread that the state authorized the dumping of over 100 million pounds of PCB-contaminated soil in the predominantly African-American county (Bullard, 2000; Mohai et al., 2009; Roberts \& Toffolon-Weiss, 2001). This prompted swift movement from activists who organized to stop the dumping and bring to the forefront the disproportionate exposure of minorities to harmful pollution as a crucial social problem. Two influential reports were subsequently commissioned (GAO, 1983; UCC, 1987) and jointly concluded that African-American communities evidenced a disproportionate concentration of hazardous waste facilities, a trend that was particularly prominent in the southern United States.

The apparent discriminatory nature of the siting of these facilities coupled with the harmful toxicity of exposure spurred scholarly interest in the location of hazardous waste facilities. Beginning with the pioneering work of Bullard (1983, 1990, 2000), a number of assessments have investigated the correlates of communities that host locally unwanted land uses (LULUs), hazardous waste facilities (Bullard et al., 2007; Mohai \& Saha, 2007), and other types of environmental hazards (Downey, 2006, 2007). Differences in methodologies, units of analysis, and types of environmental outcomes utilized have produced a rather mixed bag in terms of results that strongly support, somewhat support, or find no support for the uneven distribution of environmental hazards among racial and poverty lines (Downey, 2006). Regarding landfills, however, the more consistent finding points to the disproportionate exposure of minority communities to hazardous waste facilities (Bullard et al., 2007; Mohai \& Saha, 2007) and LULUs (Bullard, 2000), which remains significant when controlling for associated cofactors of poverty, education, income, and property value, among others. Their conclusion is that historically marginalized populations 
continue to experience injustice by exposure to environmental hazards and property devaluation; some interpret these associations as deliberate siting decisions indicative of political and institutional racial segregation.

While the focus on hazardous waste facilities (Bullard et al., 2007; Mohai \& Saha, 2007) and other noxious land uses (e.g., municipal landfills, lead smelters, chemical plants; Bullard, 2000) is indicative of the severe toxicity effects of the materials associated with them, this paper considers all land devoted to processing waste as a potential factor contributing to inequality. Quite simply, land area devoted to landfilling is unavailable for other productive uses. The transformation of natural capital (Flora \& Flora, 2013) to landfill undermines the proliferation of other (political, financial, social, human, and cultural) forms of community capital. Flora and Flora (2013) convincingly argue that natural capital - in essence, land and the life or embedded wealth it contains - is the most important of them all, based on its potential to boost all other types of capital. Landfills, then, contribute to the greatest losses of productivity and productivity potential in communities, which undermines the socioeconomic progress of the individuals in them.

Expanding the environmental inequality framework to all landfills is consequential given that for the 613 counties included in the present analysis, hazardous waste facilities comprise less than 1 percent of all landfills, whereas $C \& D$ landfills make up roughly 70 percent, and industrial and municipal landfills about 15 percent each. To reiterate, in the wake of disasters it is precisely those latter three types of landfills that are especially prone to contamination. It is of particular importance to understand the nature of the association across those communities that experience natural disasters and those that host landfills, a linkage that has not yet been explored in the sociological literature. It follows, then, that the analyses presented below examine the influence of natural disasters on the distribution of C\&D, industrial, and municipal landfills across southeastern United States counties.

We focus on the southeastern United States precisely because punctuated socioeconomic inequality (Wimberley \& Morris, 1997) and environmental injustice (Bullard, 2000; Roberts \& Toffolon-Weiss, 2001) characterize the region. The work of Wimberley and Morris (1997) demonstrates that the bulk of the nation's individuals who are poor, uneducated, impoverished, rural, and AfricanAmerican reside in southeastern counties (or what they refer to as the "Black Belt South"); these trends are confirmed to hold across space and time for various measures of inequality. The South, in general, has a distinct legacy of corporate exploitation of natural resources, cheap labor, and lax regulations, especially regarding labor and the environment (Bullard, 2000; Roberts \& Toffolon-Weiss, 2001). These trends are not unlike observed patterns of the global hierarchy of nations and the division of labor therein that relegates dirty industries and 
waste produced in the wealthy core to disadvantaged zones in the world-system for precisely the same reasons - cheap labor, abundant natural resources, and a virtual carte blanche to operate in the absence of regulation (Bunker, 1985; Frank, 1969; Wallerstein, 1974). The southeastern region in the United States, then, constitutes a "Third World" (Bullard, 2000:xv) or "peripheral" area of sorts within the United States (see e.g., Driscoll \& Kick, 2013; Smith, 1987), although we hasten to add other areas in comparable circumstances, such as Native American reservations in the west. For these reasons, the southeastern United States presents a particularly important area to examine the themes treated above; the analysis that follows empirically examines the correlates of landfill distribution across 613 counties in seven southeastern states (Alabama, Georgia, Louisiana, Mississippi, North Carolina, South Carolina, and Tennessee).

\section{Complementary theoretical approaches: Human ecology, POET and the ecological complex}

Human ecology (Park \& Burgess, 1921) is a foundational theoretical perspective that offers complementary ways of understanding the dynamics treated so far. Simply put, human ecology emphasizes the ecological embeddedness of social organization, technology, population and the environment. Particularly instructive for our purposes is the POET model as formalized by Duncan $(1959,1961)$, which identifies interdependencies among population (P), social organization/structure $(\mathrm{O})$ and technology $(\mathrm{T})$, while maintaining that all three are key causes of environmental problems (E), as well as bring consequences of one another and of the environment itself. The analysis of ecological factors as both predictors and outcomes, and the modeling of feedback loops among all terms, are key innovations.

Duncan's work $(1959,1961)$ articulates a framework in the human ecology tradition that is conceptually rich, logically compelling, derivative of hypotheses, and amenable to empirical specification and analysis. Subsequent empirical applications illustrate the viability of the POET model across a wide range of topics including, but not limited to, demography (Sly, 1972; White, 2008), disasters (Donner 2007), and agriculture (Albrecht \& Murdock, 1984). Those cases where POET is concretely applied promote testing and further theoretical refinements (e.g., Albrecht \& Murdock, 1984; Clement, 2010; Donner, 2007; Sly, 1972; York \& Mancus, 2009). The POET model's holistic approach provides a useful framework for examining the ties that integrate societal-environmental interactions, such as those elaborated below.

From a human ecology perspective, landfills may be viewed as components of both the $\mathrm{T}$ and $\mathrm{E}$ terms, as landfills represent a technology devised to manage the environmental pressure of waste. Indeed, increases in the size and density 
of a population are the mechanisms driving the need to process waste in an organized and technical manner $(\mathrm{P} \rightarrow \mathrm{E}, \mathrm{O}, \mathrm{T})$. The growing environmental burden of waste influenced social organization and technology via the creation of waste collection routes and landfills $(\mathrm{E} \rightarrow \mathrm{O}, \mathrm{T})$, and the organization of the social and technical responses to deal with waste have, in turn, impacted environmental quality in the areas where landfills are located $(\mathrm{O}, \mathrm{T} \rightarrow \mathrm{E})$. Social organization surrounding landfills reflects reductions in environmental quality via companion losses of land and housing values, in mutually reinforcing ways $(\mathrm{O} \rightarrow \mathrm{E} ; \mathrm{E} \rightarrow \mathrm{O})$. To elaborate, there is mixed evidence that the organization of political and economic institutions is such that vulnerable populations share a disproportionate burden of environmental externalities $(\mathrm{O} \rightarrow \mathrm{E})$. Concomitantly, the proximity of communities to polluting and toxic land uses reduces the value of the land and housing therein, potentially impacting the organization of the population in ways that exacerbate inequality $(\mathrm{E} \rightarrow \mathrm{O})$. There are likely additional feedback effects whereby populations reorganize themselves to escape noxious land uses, such as landfills $(\mathrm{E} \rightarrow \mathrm{P})$.

Further, environmental crises, such as natural disasters, greatly accelerate the generation of waste $(\mathrm{E} \rightarrow \mathrm{E})$ that communities must process $(\mathrm{E} \rightarrow \mathrm{T})$ in order to recover the organization of their population in the aftermath of disasters $(\mathrm{T} \rightarrow \mathrm{O}$, $\mathrm{P})$. Collective concerns surrounding disasters stimulated the organization of federal and state systems (e.g., Federal Emergency Management Agency) to standardize the response to and management of these events $(\mathrm{E} \rightarrow \mathrm{O})$. Finally, we situate within the POET framework the organizational $(\mathrm{O} \rightarrow \mathrm{E})$ and technological $(\mathrm{T} \rightarrow \mathrm{E})$ contributions to engineering disasters (Freudenburg et al., 2008) and note how these configurations exaggerate the magnitude of their calamitous effects (Perrow, 2007).

The POET model provides an extremely useful framework for conceptualizing nature-society interactions, broadly conceived, and is particularly instructive for our specific focus on the association of population (size, change), its organization (demographic characteristics and power), environmental crises (disasters), and the distribution of technical responses to manage environmental pressure (landfills). Given the burgeoning scholarship that demonstrates the political and economic dimensions that condition all factors that comprise our analytic focus such as the patterns of environmental injustice treated above, it is important to weave the POET model with a political economy lens that accounts for such dynamics. To do just that we turn to a human ecology approach to environmental inequality. 


\section{A human ecology approach to environmental inequality}

In this section we offer a preliminary interweaving of themes from the theories treated above to inform the subsequent analysis. In particular, we integrate environmental inequality emphases on the political and economic arrangements that contribute to subnational stratification with human ecology tenets that recognize the ecological embeddedness of nature-society interactions. Rather than situate these perspectives as competing explanations, our goal is to focus on their compatibilities and how they collectively improve understanding of the dynamics we test. In our view, a synthesis such as this has the potential to contribute to cumulative science in ways that improve the empirical and theoretical foundations from which they are derived. Of course, this is a modest, preliminary attempt to identify a handful of relational pathways that might be a beginning point for future refinements.

The compelling logic of the POET model and its constituent constellation of applications to diverse circumstances make it an especially powerful framework for interpreting the web of nature-society interactions. What is lacking, perhaps, is the explicit premise that each term requires concrete specification. The environmental inequality framework helps concretize the more generic POET model by articulating the political and economic arrangements that perpetuate inequality across space (Agyeman et al., 2003). Indeed, environmental inequality scholarship emerging from academic (e.g., Agyeman et al., 2003; Bullard, 2000; Mohai \& Saha, 2007) and public arenas (e.g., GAO, 1983; UCC, 1987) problematizes the unequal distribution of environmental protection and risks across subsets of the population, with specific focus on the vulnerability of marginalized communities and those that lack the political power to oppose LULUs.

Using insights from theories of environmental inequality, the POET model can be used to elaborate the ways in which biophysical conditions interact with social forces in a mutually determinative fashion. We first note that various subfields of research conclusively demonstrate differences in population (birth rates and death rates - see e.g., Thompson, 1929), organization (productive and economic - see e.g., Wallerstein, 1974), the environment (degradation and conservation - see e.g., Roberts \& Parks, 2007), and technology (its spread and its benefactors - see e.g., Volti, 2010) across nations, regions, communities, and the people in them. These themes have been interrogated to such an extent that we immediately acknowledge the abridged nature of the citations we offer. Thus, there is ample justification in observing that the POET model's general tenets are grounded by incorporating political-economic postulations on concrete differences in the distributions of interest, particularly the pronounced 
vulnerability experienced by certain segments of the population relative to others. That is, while human ecology explains the relationships among these four key dimensions, theories of environmental inequality add that there is an uneven nature to these components that impact the relationships therein (see York \& Mancus, 2009). We include in our model select factors to capture these contours in order to understand their relationships to the distribution of landfills.

\section{Data and methods}

This paper utilizes a unique data set to analyze county-level correlates to the distribution of landfills in the southeastern United States. Because many landfills are located outside of urban centers, it is requisite that the unit of analysis includes metropolitan and non-metropolitan areas. Following the tradition of highly lauded studies of regional processes (Hooks \& Smith, 2004; Tolbert et al., 1998), this paper uses county-level data that are often easier to obtain as counties are relatively stable boundaries. The inclusion of the history of disasters makes this an important consideration, so it is possible to examine cumulative associations with the outcome of interest.

We conduct OLS (ordinary least squares) regression to examine the association of relevant factors to the distribution of landfills across counties; variables are drawn from comparable prior efforts and the interweaving of the interpretations they use, as treated above. Also included in the models is the number of natural disasters in each county for the time period 1964-2011, to shed light on the relationship between a key facet of waste generation (i.e., disasters) and disposal (i.e., landfills). Our results do not allow us to identify how or why certain segments of the population suffer disproportionate exposure to landfills, but our goal instead is to analyze the county-level associations to landfill distribution. If environmental inequality does not exist, you would expect landfills to be evenly distributed across counties, irrespective of demographic and social differences.

\section{Dependent variable}

The dependent variable represents the municipal, industrial, and C\&D landfills in a county as a percentage of the cumulative total of the 1,334 landfills in the region. We employ this outcome as opposed to the count of landfills for two reasons. First, environmental justice perspectives emphasize the relative differences in the distribution of stratification. Thus, it is not the absolute number of landfills that is of substantive import, but rather it is the comparison of the relative concentration of landfills that is meaningful. Second, there is a technical complication: count outcomes such as this one that cluster around zero and have a rapidly descending upper tail are inappropriate for conventional 
analytic techniques such as OLS regression. While binary transformations could be undertaken and logistic regressions performed, doing so would dilute the precision of the data. ${ }^{11}$

The data are drawn from a variety of publicly available sources (Alabama Department of Environmental Management, 2011a, 2011b; Georgia Department of Natural Resources, 2012; Louisiana Department of Environmental Quality, 2013; Mississippi Department of Environmental Quality, 2013; North Carolina Department of Environment and Natural Resources, 2013; South Carolina Department of Health and Environmental Control, 2012; Tennessee Department of Environment and Conservation, 2013). For each state, an initial search for a directory of existing landfills was conducted at the relevant state department website (e.g., in Alabama - the Department of Environmental Management; in Louisiana - the Department of Environmental Quality). With two exceptions (Alabama and South Carolina), the list of active landfills was immediately accessible through a searchable database on the state website. The most recent data available for Alabama and South Carolina were for the year 2011; personal communication with the respective state agencies confirmed there had been no changes in the two years following the publication of those lists. For all states, contact was established with the respective environmental department to confirm the directory on the website is the most up-to-date, valid, and reliable source of information.

A comparison of the data received from individual state offices to national databases (such as the EPA's Toxic Release Inventory) revealed the greater efficiency of the former. Speaking with staff from each state's environmental office yielded more in-depth and up-to-date information than that gleaned from national databases. ${ }^{12}$ Discrepancies in state regulations further complicate data searches on the national level (i.e., EPA website) regarding C\&D and industrial landfills, as states are responsible for defining and regulating those facilities. Ostensibly, the collection of these data is best approached by directly obtaining the information from the appropriate state office. It is fortunate that the Freedom of Information Act and other right-to-know initiatives impel state offices to respond quickly to citizen inquiries such as these. As such, the data used in the analyses that follow are for the year 2013 and are taken from state branches that oversee environmental management.

11 To maintain consistency with prior efforts and in the spirit of experimentation, the analyses were re-run using the binary outcome ( $1=$ landfill; $0=$ no landfill $)$ in a logistic regression model. Conclusions remain the same; the authors will share the results with any reader who requests them.

12 As one illustration, a search for hazardous waste facilities in Alabama using the EPA's Envirofacts database returned a list of five addresses, whereas contact with the program officer in Alabama's Department of Environmental Management revealed only one of those remained in operation. After delving further to explain the contradictory information, we discovered the EPA's list had not been updated since 1994. 


\section{Independent variables}

We include the total number of federally declared disasters for each county over the period 1964-2011. ${ }^{13}$ This count includes floods, tornadoes, storms, and hurricanes. ${ }^{14}$ The data are from the Federal Emergency Management Agency (2013). To facilitate comparison with prior efforts, we include variables used in analyses of hazardous waste facilities and other LULUs in the environmental inequality literature - percent non-white in each county, percent below poverty, percent with a bachelor's degree, median household income, and median housing values - taken from the United States Census Bureau (2010). Two other variables taken from the Census Bureau are included: total county population in 2010 and the percentage change in population from 2000 to 2010 . While population is expected to have a positive, "stock effect" on landfills that has accumulated by decades, will there be a "time lag" for population change and landfills? Very large populations typically evidence comparatively small percentage-based changes in the course of a decade. Smaller bases, however, can evidence very large departures (of growth or decline) in a decade. ${ }^{15}$ We suspect an immediate growth is unlikely to be addressed in such a short period; however, decreases in population size might accompany the distribution of landfills as individuals relocate away from such land uses (e.g., "not in my backyard" (NIMBY)). It might be, then, that landfills "crowd out" human capital (read: people). Also plausible is that population declines reduce the potential for successfully organizing political opposition to LULUs. Our data do not allow us to assess the time ordering of such mechanisms, but do allow us to assess the extent to which there is an association between population change and landfills.

\section{Discussion of results}

Table 1 provides descriptive statistics and the bivariate correlation matrix of variables included in the analysis. Population and population change are shown to have positive bivariate associations with landfills, and the socioeconomic predictors are correlated in expected ways. The high correlations among the latter are a preliminary indication of multicollinearity, ${ }^{16}$ which can bias standard errors in multivariate analyses. The consequence is a greater likelihood of committing Type II errors (i.e., rejecting true hypotheses), a point returned to below.

\footnotetext{
13 This time period is chosen because the average life of a landfill is around 50 years (Allied Waste Industries, 2007), thus the years covered in the indicator is comparable to the expected life of the outcome.

14 In principle, earthquakes are also included as "disasters," but for the counties sampled there were no such events.

15 For example, a 1 percent population change in Fulton County, Georgia, (whose population is roughly one million) would require the transition of some 10,000 individuals, whereas Lanier County, Georgia, (population of around 10,000) would attain 1 percent population change with the transition of just 100 individuals.

16 To quote Bollen (1989:58), "The simple bivariate correlation between explanatory variables is not sufficient for determining the extent of collinearity. The multiple correlation of each explanatory variable regressed on the other explanatory variables comes closer to measuring this dependence."
} 


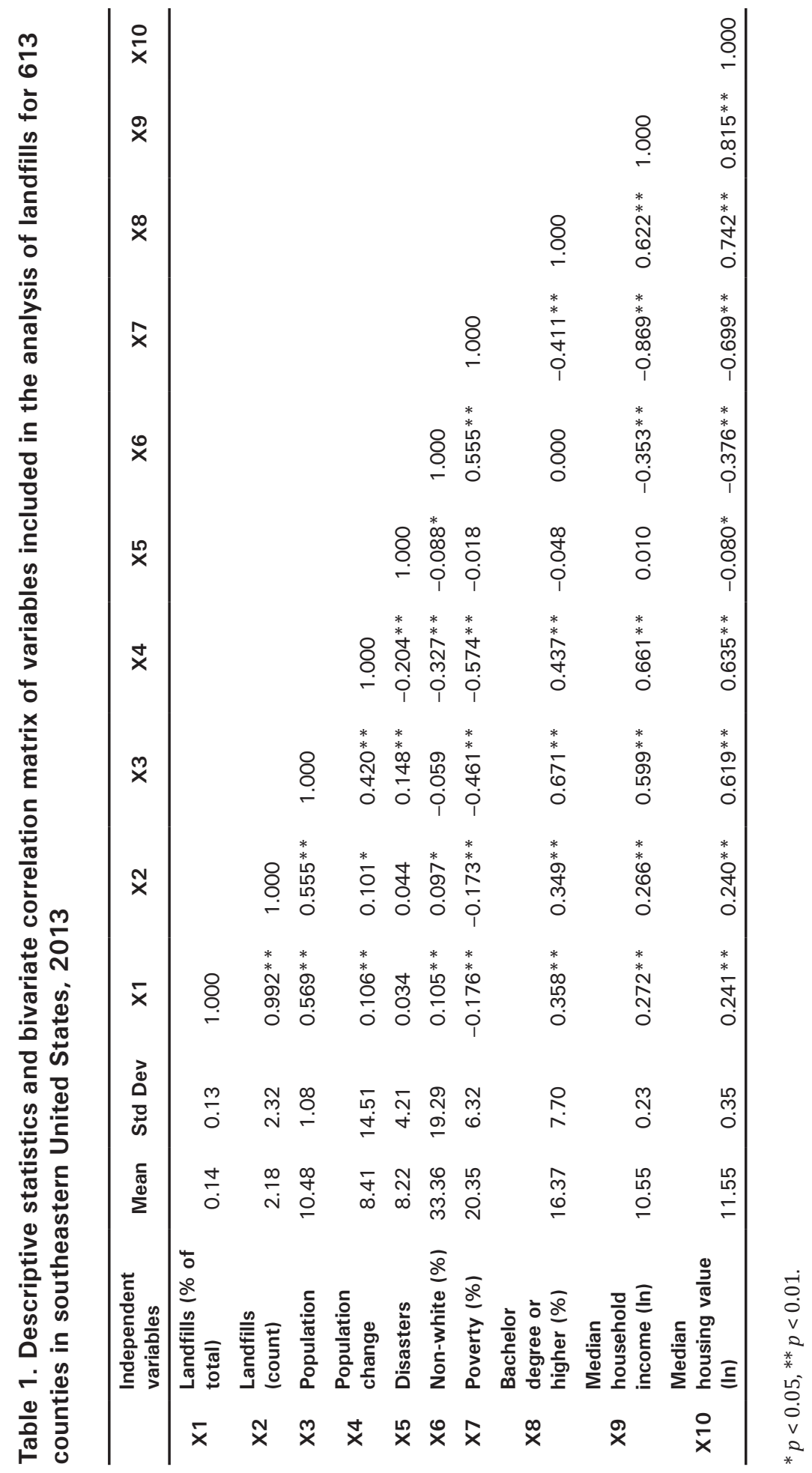


Table 2 presents the OLS coefficients, model fit indicators, and multicollinearity diagnostics for each estimation. Model 1 is taken as the best-fitted model on the basis of the F-statistic, statistical significance of the associations, and the absence of untoward collinearity. Before turning to those results, we first discuss the findings from the alternative models. Models 2, 3, 4, 5, and 6 add socioeconomic factors shown to be important in prior environmental justice studies. While these predictors are found to be non-significant (with median housing value as a partial exception in Model 3; $p<0.10$ ), the condition numbers for these models indicate unacceptable levels of multicollinearity (i.e., in excess of 30). This is suggestive of biased standard errors, which may, in part, explain the failure to find significant associations with the distribution of landfills. Thus we interpret these findings with extreme caution.

All models demonstrate consistent associations of population, population change, disasters, and percent non-white with landfill distribution. As expected, population is found to be positively associated with the distribution of landfills, which reflects the logic of human ecology and the POET model treated above. Population change is found, in all cases, to be negatively associated with the distribution of landfills. The multivariate coefficient of population change is likely indicative of areas with large population growth or declines, since large populations typically change at slower rates. We interpret this relationship as complementary to environmental inequality and human ecology perspectives, and one we anticipated from their synthesis. First, there is a general tendency to locate landfills in areas that have fewer inhabitants, including communities that experience exodus for entirely unrelated reasons. Second, environmental inequality offers that fewer people, save those with exceptional wealth or political power, will hold less sway in organizing opposition to LULUs compared to areas with rapidly growing populations. Third, advance warning of impending changes such as a new landfill may spur resident departures. ${ }^{17}$ Fourth, as stated by Hawley (1944:404), human ecology "concerns the adjustment of population to the resources and other physical conditions of the habitat." We conjecture this association is picking up on the proclivity of individuals to organize their lives in ways that avoid noxious land uses, although our analyses do not allow us to assess the temporality of such events. Importantly, this finding might be particularly consequential for rural areas that are experiencing comparatively large rates of population decline.

17 We note the potential for landfills to be repurposed post-closure to deliver a recreational amenity, such as a park or playground, which might attract new residents and improve land values. However, laws differentially regulate the timeframe for post-closure care, which is federally mandated as 30 years for municipal landfills, but varies on a state-by-state basis for industrial and C\&D landfills. Thus, we note that, in principle, there is the potential for repurposed landfills to provide a social amenity that reverses the dynamics uncovered here, although that transformation is often a decades-long process for municipal landfills and our toxicity concerns remain for those landfills in which post-closure care is determined by the state. 


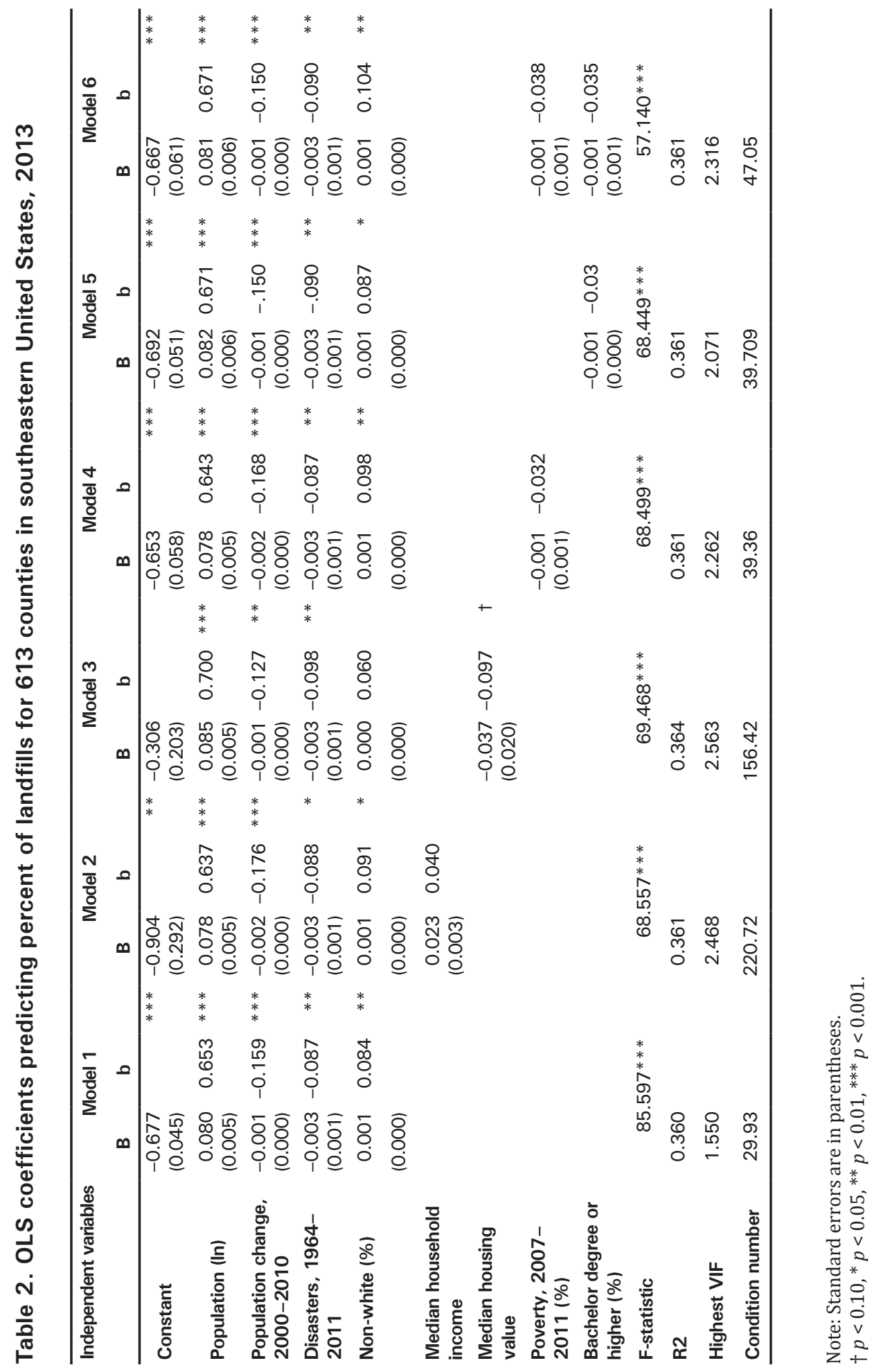


Disasters are shown in all models to be negatively associated with the outcome. That is, those counties with greater occurrences of disasters tend to have fewer landfills relative to others. Importantly, this suggests there are indirect impacts of disasters that affect other communities that process the large volumes of waste generated by these events. Percent non-white is positively associated with the distribution of landfills, indicating that counties with greater numbers of minorities are associated with a disproportionately greater concentration of landfills in the region. Our findings suggest that environmental inequality does exist because we fail to support the hypothesis that landfills are randomly distributed.

\section{Conclusions and implications}

Clearly communities directly impacted by disasters suffer an indescribable onslaught of trauma, tragedy, and socio-economic losses. This paper offers a modest step in developing the theoretical and empirical linkages between natural disasters and the disposal of waste. Given the extraordinary amounts of waste generated by such tragic events, it is important to approach these topics in a holistic manner to specify and advance the connections among these interrelated social problems. This paper weds perspectives of environmental justice and human ecology within sociology to inform an empirical analysis of the distribution of landfills in the southeastern region of the United States. Our findings indicate that disasters bear additional, indirect impacts on communities that process waste. This is an important finding and one that runs counter to conventional expectations. As climate change intensifies with predicted exacerbating effects on the occurrence and severity of extreme weather events, it is especially important to consider the indirect impacts on other areas. Further, as waste gathers in landfills more globally, greenhouse gases are emitted on a worldwide basis that, in turn, contribute to global warming trends, which then lead to intense disasters that generate large amounts of waste. Even when waste is incinerated, methane and carbon dioxide are released, further exacerbating climate change. We conclude these dynamics are best assessed in a holistic fashion that examines the relative contribution of each axis to widening gaps of inequality across communities.

Theoretically, the implication is that researchers should consider the web of linkages among the myriad causes and effects of global climate change that adversely impacts communities. The synthesis of the theoretical frameworks presented above is an especially promising undertaking for realizing this objective. In particular, we advocate the interweaving of themes from political economy perspectives (in this case, environmental inequality) with human ecology traditions (the POET model). Rather than assuming a conventional approach to constructing competing hypotheses and interpreting results as confirming or disconfirming one to the exclusion of others, we point to the 
potential for an alternative model that identifies intersections among theories and interprets results in ways that foster cumulative improvements. Indeed, critics often bemoan the failure of human ecology to incorporate and account for economic injustices and political struggles. However, it is clear the POET model leaves ample space for processes of inequality, power, and dependency. Further, we develop the case for combining the strengths of human ecology and its emphasis on biophysical processes that influence human societies with more recent articulations of political-economic dynamics that contribute to inequality. In short, we believe a POET model inspired by political-economic considerations is particularly efficacious for future work in the area.

The purpose of the analysis is not to make claims on the historical motivations for siting landfills, but rather to determine the county-level characteristics that correspond to one form of natural capital loss - the distribution of landfills. In this respect, the findings point to the heightened vulnerability of counties with larger minority presence relative to others. One possibility for future research is to investigate the historical unfolding of uneven development across subnational units to gain clarity on the precise mechanisms that collectively worsen conditions for certain segments of the population, especially land-use decisions related to disaster waste management. Historical case studies and ethnographies of communities are especially promising avenues for uncovering such dynamics. Additionally, analyses might be replicated in different contexts to inform a comparison of regions in the United States; they might also be undertaken at other levels of aggregation to discern if those refinements lead to the same conclusions as those reached here.

While we do not test the mechanisms that produce inequalities over time, our results point to the non-random distribution of landfills across the southeastern region that, in future analyses, could be linked to socio-economic indicators of progress and human health outcomes of fundamental importance to environmental justice (Brulle \& Pellow, 2006). Put differently, the distribution of landfills as both a predictor and outcome of various axes of inequality across communities is a fruitful direction for future research to explore. Moreover, further investigation into the nuances of the association between population change and landfills seems warranted to clarify the chronology of events and the influence of socioeconomic factors. For instance, if landfills spur countylevel declines in population, what segments of the population are able to move away from LULUs, and how do socio-economic factors affect this decision?

Environmental inequality treatments acknowledge the importance of using empirical research to initiate public policy debates and future directions. In this vein, one implication of our findings might be that federal and local disaster management bodies should consider directing relief efforts to communities receiving disaster waste, and craft policies that protect the land, socio-economic progress, productivity potential, and the health and well-being of those 
communities. Doing so also requires a holistic approach to mitigating the effects of disasters, including the waste that results from these tragedies. A singular focus on the direct, immediate effects on the areas where the events occur does not achieve the desired result. Rather, it is the understanding of the interlinkages among disasters, waste, and landfill disposal that is most auspicious for boosting the sustainability of all communities affected by myriad outcomes associated with disasters. It is important to note that the "ecological complex" and the POET model as presented by Duncan $(1959,1961)$ is a particularly persuasive and useful framework for conceiving such connections. Future analyses might benefit from the integration of theories as presented here, to test a wide range of outcomes related to the social, economic, and environmental sustainability of individuals and the communities in which they are embedded.

Methodologically, the analyses presented demonstrate the technical complications that arise when models include indicators that evidence untoward levels of collinearity. While the quantitative analyses presented show a notable amount of consistency with prior, related efforts, the multicollinearity diagnostics (variance inflation factors, condition numbers) throw caution on the interpretation of models 2-6. Although imperfect indicators of collinearity, these are serious considerations that can affect results, conclusions, and public policy implications. Future research might incorporate alternative estimation techniques that reduce multicollinearity in models through, for instance, the inclusion of latent or composite indicators. It might be that percent non-white, poverty, household income, and housing values are cognate indicators of inequality that when modeled as a composite variable ranks as a chief predictor of environmental inequality. Structural equation modeling is one estimation technique that allows the researcher to specify latent variables (measurement model) within a structural (path) model.

The analysis presented links disasters and socio-economic factors to the distribution of landfills in the southeastern United States, yet the conclusions drawn from the results should be taken as only a preliminary starting point for further empirical research. We advocate further work in the area and provide a range of possibilities above. More generally, we see great utility in playing less part in the nearly universally employed "gladiator" approach to hypothesis testing, coupled with support, instead, for the adoption of integrative approaches to theory and empirics that highlight the compatibilities, reciprocities, and potential for synthesis among relevant explanations. Although we could envision contention between much more holistic packages of carefully integrated hypotheses that form overarching approaches, we believe this has potential for advancing the accumulation of knowledge. As theoretical and empirical developments accrue, sociology has the potential to advance understanding of nature-societal interactions that might improve disaster and waste management 
in ways that enhance the sustainability of communities and individuals who face the challenges presented by significant social problems discussed in this paper.

\section{References}

Agyeman, J., Bullard, R. D., \& Evans, B. (Eds.). (2003). Just sustainabilities: Development in an unequal world. Cambridge, MA: MIT Press.

Alabama Department of Environmental Management. (2011a). Permitted construction/demolition landfills and industrial landfills in the State of Alabama. Montgomery, AL: Solid Waste Branch, Land Division, Alabama Department of Environmental Management. Retrieved from http://www. adem.state.al.us/programs/land/landforms/CDILFMasterList08-11.pdf.

Alabama Department of Environmental Management. (2011b). Permitted municipal solid waste landfills in the State of Alabama. Montgomery, AL: Solid Waste Branch, Land Division, Alabama Department of Environmental Management. Retrieved from http://www.adem.state.al.us/programs/land/ landforms/MSWLFMasterList08-11.pdf.

Albrecht, D., \& Murdock, S. (1984). Toward a human ecological perspective on part-time farming. Rural Sociology, 49(3), 389-411.

Allied Waste Industries. 2007. Form 10-K. Annual report 2006. United States Securities and Exchange Commission. Retrieved from http://www.sec.gov/ Archives/edgar/data/848865/000095015307000379/p73468el0vk.htm.

Bollen, K. (1989). Structural equation models. John Wiley \& Sons, Ltd.

Brown, C., Milke, M., \& Seville, E. (2011). Disaster waste management: A review article. Waste management, 31(6), 1085-1098.

Brulle, R., \& Pellow, D. (2006). Environmental justice: Human health and environmental inequalities. Annual Review of Public Health, 27, 103-124.

Bullard, R. (1983). Solid waste sites and the black Houston community. Sociological Inquiry, 53(2-3), 273-288.

Bullard, R. (1990). Dumping in Dixie: Race, class, and environmental quality. Boulder, CO: Westview Press.

Bullard, R. D. (2000). Dumping in Dixie: Race, class, and environmental quality (3rd ed.). Boulder, CO: Westview Press.

Bullard, R., Mohai, P., Saha, R., \& Wright, B. (2007). Toxic wastes and race at twenty: 1987-2007. United Church of Christ Justice and Witness Ministries. 
Bunker, S. G. (1985). Underdeveloping the Amazon: Extraction, unequal exchange, and the failure of the modern state. Urbana, IL: University of Illinois Press.

Clement, M. (2010). A critical human ecology of water use at the county-level in Texas, 2002. Human Ecology Review, 17(1), 34-43.

Donner, W. R. (2007). The political ecology of disaster: An analysis of factors influencing U.S. tornado fatalities and injuries, 1998-2000. Demography, 44(3), 669-685.

Downey, L. (2006). Environmental inequality in metropolitan America in 2000. Sociology Spectrum, 26(1), 21-41.

Downey, L. (2007). US metropolitan-area variation in environmental inequality outcomes. Urban Studies, 44(5-6), 953-977.

Driscoll, A., \& Kick, E. (2013). Naval stores extraction in eastern North Carolina: The historical basis of spatial inequality within a core nation. Journal of World-Systems Research, 19(1), 1-24.

Duncan, O. (1959). Human ecology and population studies. In P. M. Hauser \& O. D. Duncan (eds), The study of population (pp. 678-716). Chicago: University of Chicago Press.

Duncan, O. (1961). From social system to ecosystem. Sociological Inquiry, 31, $140-149$.

Eaton, L. (2006, August 16). New Orleans mayor closes a disputed landfill used for debris from hurricane. The New York Times. Retrieved from http://www. nytimes.com/2006/08/16/us/16orleans.html.

EPA (United States Environmental Protection Agency). (2006). Solid waste management and greenhouse gases: A life-cycle assessment of emissions and sinks (3rd ed.). EPA.

EPA (United States Environmental Protection Agency). (2008). Planning for natural disaster debris guidance (Document ID Number EPA530-K-08-001). Office of Solid Waste and Emergency Response, EPA.

EPA (United States Environmental Protection Agency). (2013a). Climate change and waste (Document ID Number EPA 530-E-03-002). Office of Solid Waste and Emergency Response, EPA.

EPA (United States Environmental Protection Agency). (2013b). Municipal solid waste generation, recycling, and disposal in the United States: Facts and figures for 2011 (Document ID Number EPA 530-F-13-001). Office of Solid Waste and Emergency Response, EPA. 
Federal Emergency Management Agency. (2013). Disaster declarations. Washington, DC: Government Printing Office.

Flora, C., \& Flora, J. (2013). Rural communities: Legacy and change. Boulder, CO: Westview Press.

Forster, P., Ramaswamy, V., Artaxo, P., Berntsen, T., Betts, R., Fahey, D. W. ... Van Dorland, R. (2007). Changes in atmospheric constituents and radiative forcing. In S. Solomon, D. Qin, M. Manning, M. Marquis, K. Averyt, M. M. B. Tignor, H. L. Miller Jr. \& Z. Chen (eds), Climate change 2007: The physical science basis (pp. 129-234). Cambridge, UK: Cambridge University Press.

Fothergill, A., \& Peek, L. (2004). Poverty and disasters in the United States: A review of recent sociological findings. Natural Hazards, 32(1), 89-110.

Frank, A. (1969). The development of underdevelopment. Bobbs-Merrill.

Freudenburg, W. R., Gramling, R., Laska, S., \& Erikson, K. T. (2008). Organizing hazards, engineering disasters? Improving the recognition of politicaleconomic factors in the creation of disasters. Social Forces, 87(2), 1015-1038.

GAO (United States General Accounting Office). (1983). Siting of hazardous waste landfills and their correlation with racial and economic status of surrounding communities. Gaithersburg, MD: GAO.

Georgia Department of Natural Resources. (2012). List of solid waste disposal facilities. Environmental Protection Division. Retrieved from http://epd. georgia.gov/solid-waste.

Hawley, A. (1944). Ecology and human ecology. Social Forces, 22(4), 398-405.

Hogan, K., Hoffman, J., \& Thompson, A. (1991). Methane on the greenhouse agenda. Nature, 354, 181-182.

Hooks, G., \& Smith C. (2004). The treadmill of destruction: National sacrifice areas and Native Americans. American Sociological Review, 69(4), 558-575.

IPCC (Intergovernmental Panel on Climate Change). (2007). IPCC fourth assessment report: Climate change 2007 (AR4). Geneva: IPCC.

Lelieveld, J. (2006). A nasty surprise in the greenhouse. Nature, 443, 405-406.

Louisiana Department of Environmental Quality. (2013). Solid waste landfill report. Waste Permits Division. Retrieved from http://www. deq.louisiana.gov/portal/DIVISIONS/WastePermits/SolidWastePermits/ SolidWasteLandfillReport.aspx. 
Luther, L. (2008). Managing disaster debris: Overview of regulatory requirements, agency roles, and selected challenges. Washington, DC: Congressional Research Service, Library of Congress.

Mississippi Department of Environmental Quality. (2013). State of Mississippi solid waste management facilities listing. Solid Waste Management Program. Retrieved from http://www.deq.state.ms.us/MDEQ.nsf/pdf/SW_ ActiveFacilityListing/\$File/ActiveFacilityListing.pdf?OpenElement.

Mohai, P., Pellow, D., \& Roberts, J. T. (2009). Environmental justice. Annual Review of Environment and Resources, 34, 405-430.

Mohai, P., \& Saha, R. (2007). Racial inequality in the distribution of hazardous waste: A national-level reassessment. Social problems, 54(3), 343-370.

North Carolina Department of Environment and Natural Resources. (2013). Waste data and facility lists. Retrieved from http://www.wastenotnc.org/ web/guest/data-statistics-reports-and-maps.

Park, R., \& Burgess, E. (1921). Introduction to the science of sociology. Chicago: University of Chicago Press.

Perrow, C. (2007). The next catastrophe: Reducing our vulnerabilities to natural, industrial, and terrorist disasters. Princeton, NJ: Princeton University Press.

Roberts, J. T., \& Parks, B. C. (2007). A climate of injustice: Global inequality, north-south politics, and climate policy. Cambridge, MA: The MIT Press.

Roberts, J. T., \& Toffolon-Weiss, M. (2001). Chronicles from the environmental justice frontline. Cambridge, UK: Cambridge University Press.

Rudel, T., Roberts, J. T., \& Carmin, J. (2011). Political economy of the environment. Annual Review of Sociology, 37, 221-238.

Russell, G. (2012, September 27). Hurricane Katrina was a bonanza for local landfills, and River Birch fought to get every scrap of debris. nola.com/ The Times-Picayune. Retrieved from http://www.nola.com/politics/index. ssf/2012/09/hurricane_katrina_was_a_bonanz.html.

Sly, D. (1972). Migration and the ecological complex. American Sociological Review, 37, 615-628.

Smith, D. (1987). Dependent urbanization in colonial America: The case of Charleston, South Carolina. Social Forces, 66(1), 1-28.

South Carolina Department of Health and Environmental Control. (2012). South Carolina solid waste management annual report. Retrieved from http://www. scdhec.gov/environment/lwm/recycle/pubs/swm_FY12_ALL.pdf. 
Tennessee Department of Environment and Conservation. (2013). Permitted solid waste facilities. Division of Solid and Hazardous Waste Management. Retrieved from http://environment-online.state.tn.us:8080/pls/enf_reports/ $\mathrm{f} ? \mathrm{p}=19035: 34001: 0::::$.

Thompson, W. (1929). Recent trends in world population. American Journal of Sociology, 34, 959-979.

Tierney, K. (2012). Disaster governance: Social, political, and economic dimensions. Annual Review of Environment and Resources, 37, 341-363.

Tolbert, C., Lyson, T., \& Irwin, M. (1998). Local capitalism, civic engagement, and socioeconomic well-being. Social Forces, 77(2), 401-427.

UCC (United Church of Christ). (1987). Toxic wastes and race in the United States. New York: Commission for Racial Justice, United Church of Christ.

United States Census Bureau. (2010). Characteristics of population (Vol. 1). Washington, DC: Government Printing Office.

Volti, R. (2010). Society and technological change (6th ed.). New York: Worth Publishers.

Wallerstein, I. (1974). The modern world-system: Capitalist agriculture and the origins of the European world-economy in the sixteenth century. Academic Press.

White, K. J. C. (2008). Sending or receiving stations? The dual influence of railroads in early 20th-century great plains settlement. Population Research and Policy Review, 27(1), 89-115.

Wimberley, R., \& Morris, L. (1997). The southern black belt: A national perspective. Lexington, KY: TVA Rural Studies.

York, R., \& Mancus, P. (2009). Critical human ecology: Historical materialism and natural laws. Sociological Theory, 27(2), 122-149. 
This text taken from Human Ecology Review Volume 21, Number 1, 2015, published 2015 by ANU Press, The Australian National University, Canberra, Australia. 